\title{
Padrões setoriais de mudança técnica e fomento de inovações na indústria brasileira: considerações sobre o setor automotivo
}

\author{
Almir Cléydison Joaquim da Silva* \\ Mônica Aparecida Bortolotti** \\ Walter Tadahiro Shima ${ }^{* * *}$
}

\begin{abstract}
Resumo
O presente trabalho procura apresentar uma discussão relacionada aos padrões setoriais de mudança técnica e fomento de inovações no setor automotivo brasileiro. A partir da concepção de que concorrência pressupõe fundamentalmente inovação, as experiências observadas no setor automotivo brasileiro são discutidas por meio de uma abordagem que envolve os elementos de organização do setor, interação com outros setores e fornecedores, assim como os principais aspectos de produção e desenvolvimento de inovações ao longo do tempo. Enquanto elemento analítico, considera-se a classificação da taxonomia para as empresas de Pavitt (1984), que compreende os setores dominados por fornecedores, produção intensiva e baseados na ciência. Conclui-se indicando que o setor automotivo, embora classificado na taxonomia de produção intensiva, mantém e necessita de uma forte interligação com outras categorias da taxonomia, especialmente dos setores baseados na ciência, que contribuem para o processo de mudança técnica em toda cadeia automotiva. E no que concerne ao fomento e disseminação de inovações no setor, destaca-se a importância de políticas públicas e estratégias de desenvolvimento industrial direcionadas para estímulo à pesquisa e desenvolvimento, com foco nas principais tendências e rotas tecnológicas que têm surgido no contexto das economias globalizadas.
\end{abstract}

Palavras-chave: tecnologia e inovação; padrões setoriais; indústria automotiva.

\section{Sectoral patterns of technical change and innovation promotion in the Brazilian industry: considerations about the automotive sector}

\begin{abstract}
The present paper seeks to present a discussion related to the sectoral patterns of technical change and fomenting innovations in the Brazilian automotive sector. From the conception that competition presupposes fundamental innovation, the experiences observed in the Brazilian automotive sector are discussed through an approach that involves the elements of organization of the sector, interaction with other sectors and suppliers, as well as the main aspects of production and development of innovations over time. As an analytical element, we consider the classification of taxonomy for firms by Pavitt (1984), which comprises the sectors dominated by suppliers, intensive production and science-based. It concludes by indicating that the automotive sector, although classified in the intensive production taxonomy, maintains and needs a strong interconnection with other categories of taxonomy, especially the science-based sectors, that contribute to the process of technical change in the entire automotive chain. And with regard to the promotion and dissemination of innovations in the sector, the importance of public policies and industrial development strategies directed to stimulate

\footnotetext{
* Economista pela UFPB e mestrando em Políticas Públicas pela UFPR. E-mail: almirjoaquim@gmail.com

** Economista e mestre em Extensão Rural pela UFSM, mestre em Desenvolvimento Regional pela UTFPR e doutoranda em Políticas Públicas pela UFPR. E-mail: monica_economia@yahoo.com.br

**** Doutor em Economia da Indústria e da Tecnologia pela UFRJ, professor do departamento de Economia e do Programa de Pós-Graduação em Políticas Públicas da UFPR. E-mail: waltershima @ufpr.br
} 
research and development, focusing on the main trends and technological routes that have emerged in the context of globalized economies.

Keywords: technology and inovation; sectorial patterns; automotive industry.

JEL Classification: L00, L62

\section{Introdução}

Discussões sobre inovação tecnológica têm cada vez mais ganhado espaço no âmbito econômico e empresarial, onde a inovação tem-se configurado enquanto elemento dinâmico e determinante da concorrência, sendo responsável por mudanças estruturais (ROSENBERG, 1994). Ao analisar algumas hipóteses schumpeterianas, Kamien e Schwartz (1982) chamam a atenção ao fator inovação enquanto meio decisivo para se obter vantagens sobre concorrentes. Esses argumentos vão em sentido contrário a abordagens da economia neoclássica de concorrência via preço, ou, de uma forma mais ampla, da perspectiva de análise da economia enquanto um processo estacionário, embasado no equilíbrio geral dos mercados.

Os estudos sobre mudança técnica (ou tecnológica) têm permitido avanços na compreensão de regularidades e comportamentos setoriais atrelados à inovação. Mudança tecnológica refere-se ao "[...] lançamento ou aprimoramento de produtos, processos produtivos, métodos gerenciais ou uso de insumos e matérias-primas modificadas" (CAMPOS; RUIZ, 2009, p. 169). Mudança técnica também está fortemente interligada com o processo cumulativo de empresas e setores, ou seja, com o conhecimento técnico adquirido ao longo do tempo e em projetos realizados anteriormente (PAVITT, 1984; 1994).

A inovação no processo industrial se apresenta através de novos processos atrelados a formas de organização produtiva, impulsionadas pelos mercados e as possíveis fontes de matéria-prima, que configuram e estruturaram as estratégias elementares para a competitividade na concorrência capitalista. Por conseguinte, a inovação não contempla apenas a inclusão de novos produtos e serviços no mercado, mas também todos os esforços destinados à incorporação e ao desenvolvimento do que já existe, ou seja, a inovação envolve os processos de invenção, inovação, difusão e inovação incremental (GUIDOLIN, 2007).

No âmbito da literatura neoschumpeteriana, Pavitt (1984) constitui-se como um dos principais autores da descrição do processo de inovação e mudanças tecnológicas no setor industrial. Avanços consideráveis são destacados pelo autor, tanto na demonstração de como os setores absorvem a tecnologia quanto sobre como conduzem e difundem as atividades de 
inovação. Por conseguinte, atenção considerada é atribuída, neste trabalho, à taxonomia para as empresas ou setores proposta por Pavitt.

Neste contexto, o presente trabalho apresenta uma discussão de aspectos relacionados a padrões setoriais de mudança técnica e fomento a inovações, a partir da observação dos processos de disseminação de inovações na indústria automotiva brasileira.

Além dessa introdução, o trabalho encontra-se estruturado em mais três seções. A segunda apresenta uma revisão teórica envolvendo os principais aspectos e características da dinâmica industrial, intervenção estatal, tecnologia e inovação, partindo-se da concepção de que concorrência pressupõe fundamentalmente inovação. Na terceira seção, destacam-se elementos de progresso técnico, trajetórias tecnológicas e a classificação da taxonomia para os setores de Pavitt (1984), a saber: 1) dominados por fornecedores; 2) produção intensiva e; 3) baseados na ciência. Esta taxonomia é utilizada enquanto elemento analítico para o desenvolvimento do trabalho em questão. Por conseguinte, na quarta seção apresentam-se considerações sobre a experiência do setor automotivo brasileiro, procurando destacar o potencial das novas rotas tecnológicas. Considera-se ainda, uma contextualização dos elementos de organização do setor, interação com outros setores e fornecedores, assim como os principais aspectos de produção e desenvolvimento de inovações ao longo do tempo, procurando discutir dentro da classificação de taxonomia proposta por Pavitt. Por fim, a quinta seção contempla as considerações finais.

\section{Tecnologia, inovação e fomento a setores de atividade econômica por parte do Estado}

Historicamente, as estratégias e experiências de industrialização, tanto em países desenvolvidos quanto em países em desenvolvimento, indicam a importância da intervenção estatal no fomento e estímulo ao desenvolvimento de setores considerados estratégicos para a economia dos países. Isso configura o que Mazzucato (2014) destaca como o "Estado empreendedor", ou seja, o papel de impulsionador da capacidade empresarial, a partir da criação de condições estruturais que facilite o processo inovativo.

Em período recente, observa-se que a tendência para o desenvolvimento dos países, em geral, está intimamente relacionada com a participação e intervenção do Estado em estimular o desenvolvimento da Ciência e Tecnologia (C\&T). Por conseguinte, C\&T têm cada vez mais se apresentado como variável dependente da reação do capitalismo, que necessita de um constante processo de inovação, especialmente com a intensificação das economias globalizadas. 
As preocupações em inserir a temática da tecnologia e da inovação nas políticas de desenvolvimento industrial passaram a surgir de forma sistemática a partir do início dos anos 2000. Neste contexto, ressalta-se a observação de Cunha (1992, p. 86) ao fato de que "[...] a Política de Ciência e Tecnologia só se concretiza se a sua base de formulação estiver assentada na vontade política, tendo como sustentação um projeto nacional que defina o grau de dependência tecnológica desejada para a nação".

A esse respeito, destaca-se que a conjuntura, interna e externa, favorável durante os governos do presidente Luiz Inácio Lula da Silva (2003-2010) possibilitou a implementação de estratégias de desenvolvimento industrial mais coordenadas, a saber: a) Política Industrial, Tecnológica e de Comércio Exterior (PITCE), de 2007 a 2007, e; b) Política de Desenvolvimento Produtivo (PDP), de 2008 a 2010. A PITCE traçou estratégias para os setores de software, semicondutores, fármacos e bens de capital, assim como possibilitou melhorias em infraestrutura, a concessão de incentivos fiscais e ampliação do diálogo com as políticas de comércio exterior. Já com a PDP, observou-se uma ampliação das ações estratégicas para diversos outros setores da matriz industrial brasileira ${ }^{1}$. Além disso, a PDP também visou à elevação da competitividade do país e a geração de emprego. Durante o governo da presidente Dilma Rousseff (2011-2016), a política industrial, tecnológica e de comércio exterior foi direcionada pelo Plano Brasil Maior (PBM), o qual teve foco em medidas setoriais ${ }^{2}$ para o estímulo ao desenvolvimento do país (MATTOS, 2013; CORONEL; AZEVEDO; CAMPOS, 2014; BRASIL, 2016; BNDES, 2016).

Não obstante, cabem também observações referentes às configurações institucionais, as quais assumem arranjos diferenciados e podem envolver padrões alternativos de conduta e articulação com o Estado, o setor privado e a sociedade civil em geral. Por conseguinte, esses padrões alternativos são pautados e marcados pela evolução econômica, ou seja, por um processo de sincronização entre tecnologias, empresas, mercado e instituições, que seguem trajetórias econômicas estabelecidas (NELSON, 1994).

\footnotetext{
${ }^{1}$ A PDP contemplou vinte e quatro setores da indústria brasileira, conforme apontado por Coronel, Azevedo e Campos (2014, p. 113): “Aeronáutico; Agroindústria; Bens de Capital; Bioetanol; Biotecnologia; Carnes; Celulose e Papel; Complexo Automotivo; Complexo de Defesa; Complexo de Serviços; Complexo da Saúde; Construção Civil; Couro, Calçados e Artefatos; Energia Nuclear; Higiene, Perfumaria e Cosméticos; Indústria Naval e de Cabotagem; Madeiras e Móveis; Mineração; Nanotecnologia; Petróleo, Gás e Petroquímica; Plásticos; Siderurgia; Têxtil e Confecções; e Tecnologia da Informação e Comunicação."

${ }^{2}$ Dezenove setores foram priorizados pelo PBM, conforme segue: petróleo, gás e naval; complexo da saúde; automotivo; defesa, aeronáutica, espacial; bens de capital; tecnologia da informação e comunicação (TIC) e complexo eletroeletrônico; química; energias renováveis; indústria da mineração; metalurgia; papel e celulose; higiene pessoal, perfumaria e cosméticos; couro, calçados, têxtil, confecções, gemas e jóias; móveis; construção civil; agroindústria; comércio; serviços e; serviços logísticos (BRASIL, 2016; MATTOS, 2013).
} 
Os componentes centrais para a dinâmica da evolução, de acordo com Nelson e Winter (1982), referem-se ao processo de geração de variedade tecnológica através da atividade inovadora. A seleção destas atividades tecnológicas é exercida pelo mercado e sua intensidade depende do acirramento das forças de seleção do processo capitalista, nos produtos e nas organizações. Por figurar como um processo seletivo de interesses e prioridades, cabe ao Estado fazer a escolha.

Com relação às dimensões da inovação e da atuação pública, destacam-se as forças evolutivas relacionadas à variedade e a seleção. A respeito da variedade, existem duas ações genéricas que são potencializadas e focalizadas, a saber: a) a promoção das inovações paradigmáticas, e; b) a promoção de inovações incrementais. A primeira envolve o desenvolvimento da infraestrutura de C\&T, além do estímulo a projetos exploratórios de Pesquisa e Desenvolvimento (P\&D) e o fomento de instituições que servirão de ponte, considerando o surgimento de oportunidades inovadoras. Enquanto que a segunda promove o estímulo a ganhos cumulativos ao nível de empresas e setores, ou seja, proporciona ganhos de produtividade e processos de aperfeiçoamento de qualidade (NELSON; WINTER, 1982; DOSI, 1984; PAVITT, 1984).

Já com relação à seleção, a atuação pública centra-se no fortalecimento e crescimento do ator inovador, que, ao adquirir as condições de produzir sem uma intervenção direta dos demais agentes, ou seja, o poder de explorar o mercado dado o incentivo pela inovação, reflete a importância da atuação pública em termos de possibilidade de crescimento de atores inovadores no mercado. Outra ação é o favorecimento de condições adequadas para os que se tornam imitadores das inovações. Essa ação ocorre com o estímulo para a inovação difusora, que permite uma participação maior de empresas e pessoas no mercado, enquanto consequência do processo de inovação (NELSON; WINTER, 1982; DOSI, 1984; PAVITT, 1984).

Existe também a condição em que o Estado necessita fazer escolhas (trade offs) entre a variedade versus a seleção e entre a apropriação versus a imitação. No primeiro caso, a variedade versus a seleção, é necessário um equilíbrio entre o dinamismo inovador exercido pelo mercado e o poder seletivo que a concorrência exerce no que tange ao estímulo da inovação pemanente, que é paradigmática e incremental. Por outro lado, este equilíbrio evita que a inovação fique estagnada (lock in), além de estimular que a seleção de inovações superiores aconteça no interior das firmas. Isso proporciona tanto a difusão quanto a entrada de novas firmas no mercado, onde as mesmas serão difundidas ou promovidas a partir da existência de iniciativas tecnológicas, e diversidade atrelada ao poder de seleção de mercado. 
Este, por conseguinte, irá classificar as tecnologias como superiores ou inferiores (NELSON; WINTER, 1982; DOSI, 1984; PAVITT, 1984).

Enquanto que no segundo caso, apropriacionismo versus a imitação, a escolha passa a exigir a ação de balanceamento entre o estímulo à difusão e a apropriabilidade das inovações. Este balanceamente deve estimular os inovadores e também preservar a capacidade de adoção dos imitadores. Podem ainda ser acompanhados por indicadores de apropriabilidade, lucratividade - que se verifica no mercado - e indicadores de difusão - que representam o acesso às novas tecnologias (NELSON; WINTER, 1982; DOSI, 1984; PAVITT, 1984).

No que concerne à atuação pública na dinâmica de inovação das estruturas produtivas, cabe destacar a diferenciação existente entre países inovadores e países imitadores, que, por sua vez, também consideram a variedade e a seleção como forças evolutivas. Em países inovadores, a variedade do processo de inovação ocorre de forma paradigmática em áreas de fronteiras e em áreas de alta oportunidade e cumulatividade, assim como pela seleção, especialmente através do estímulo causado pela apropriabilidade e a elevada pressão sobre a competitividade. Já em países imitadores, o processo de variação, por um lado, é consequência do esforço de absorção de trajetórias já consolidadas e da introdução de novas tecnologias ou aprimoramentos, assim como do estímulo para a exploração de novas oportunidades de mercado. Enquanto que a seleção, por outro lado, é um estímulo à difusão e às pressões competitivas de mercado (DOSI, 1984; PAVITT, 1984).

Em síntese, observa-se que as escolhas que ocorrem entre países inovadores e países imitadores - sobre aspectos de variedade, seleção, apropriação e imitação - seguem a seguinte trajetória: i) em países inovadores prevalece à variedade, e em países imitadores, a seleção; e ii) em países inovadores existe a predominância da apropriabilidade, e em países imitadores, o predomínio da imitação (DOSI, 1984; PAVITT,1984). Por outro lado, Prebisch (2000, p. 83) complementa este raciocínio afirmando que “[...] enquanto os centros preservaram integralmente o fruto do progresso técnico de sua indústria, os países periféricos transferiram para eles uma parte do fruto do seu próprio progresso técnico".

De acordo com a Confederação Nacional da Indústria (CNI), “[...] a inovação é considerada inequívoca para as empresas competirem nos mercados globais, gerando ganhos significativos de produtividade" (CNI, 2014, p. 5). Neste sentido, a inovação proporciona a geração de vagas de empregos mais qualificados, um aumento gradativo e sustentável da renda, tanto fortalecendo o setor industrial quanto promovendo a melhora da qualidade de vida de toda a população (CNI, 2014). Entretanto, para que isso possa ser viabilizado, existe a necessidade de contribuições do Estado, direta ou indiretamente, com a concessão de 
incentivos e/ou através de políticas macroeconômicas para estimular o desenvolvimento econômico e a promoção da inovação.

Canêdo-Pinheiro (2013, p. 402) escreve sobre os incentivos das políticas industriais e as consequentes externalidades positivas e negativas que podem gerar. Para tanto, destaca que a “[...] proteção excessiva por tempo indeterminado, ausência de metas e regras de saída, barreiras para importação de insumos e adoção de novas tecnologias - características típicas da experiência brasileira - parecem ser a receita certa para o fracasso".

Dentro deste contexto, cabe fazer menção ao relatório de nota técnica, intitulado “Análise do Plano Brasil Maior (PBM)”, elaborado por Mattos (2013) com base em dados do Ministério do Desenvolvimento, Indústria e Comércio Exterior (MDIC), onde se destacam as prioridades do PBM em relação às categorias, aos setores, à ênfase e ao tipo de programa.

Três categorias são enfatizadas. A primeira categoria é o sistema onde o Brasil tem reconhecida competência, que engloba os setores de aeronáutica, petróleo, gás natural e petroquímica, bioetanol, mineração, celulose e papel, siderurgia e carnes. Nestes setores, a ênfase é em consequência do poder da capacidade produtiva, da exportação crescente, da internacionalização empresarial, bem como da liderança tecnológica. A segunda categoria contempla os sistemas geradores de encadeamentos, intermediários, o qual tem potencial competitivo exportador e/ou importador (setor automotivo, bens de capital, indústria naval e cabotagem, têxtil e confecções, couro, calçados e artefatos, madeira e móveis, agricultura, construção civil, complexo serviços, higiene, perfumaria e cosméticos, plásticos), em que a expansão da produção, das exportações e da capacidade inovadora está direcionada para o fortalecimento da competitividade entre empresas nacionais e multinacionais. Enquanto que, em uma última categoria, contemplam-se os sistemas intensivos em C\&T, afetados por importações, mas com potencial competitivo (complexo indústria da saúde, nanotecnologia, tecnologias de informação e comunicação, energia nuclear, biotecnologia, complexo indústria de defesa), nos quais a capacitação e a competitividade entre os elos relevantes da cadeia de inovação promovem as áreas estratégicas (MATTOS, 2013).

Por fim, ressalta-se a importância estatal no fomento e condução de estratégias de desenvolvimento industrial, tecnológico e de inovação. Contudo, o Estado ainda precisa reconhecer sua importância e assumir posturas mais proativas junto aos setores beneficiados. Mattos (2013, p. 4) chama a atenção para o fato de que "[...] a chance de uma política industrial dar certo está na medida da capacidade institucional do Estado em definir e cobrar contrapartida/desempenho mínimo dos beneficiários”. Nesse sentido, chama-se a atenção para os ajustes que ainda se fazem necessários na intervenção estatal e na consequente relação 
estabelecida entre Estado e classe empresarial, especialmente vinculados a incentivos e punições, alcance de metas e tempo de proteção.

\section{Progresso técnico, trajetórias tecnológicas e uma taxonomia de padrões setoriais de mudança técnica}

Os estudos e investigações ligados ao progresso técnico estiveram por muito tempo associados, na abordagem neoclássica, à análise de elementos e fatores exógenos aos fenômenos econômicos, sendo compreendidos de forma indireta. Pela nova concepção neoclássica, o progresso técnico sai de uma concepção de bem público e passa para uma visão de bem semi-público. Nesta perspectiva, o conhecimento tecnológico é distinguido entre: a) informações técnicas específicas, que são de propriedade das firmas e garantidas por leis de patentes, onde a informação pode enquadrar-se como um bem excludente; e b) informações técnicas gerais, provocando externalidades tecnológicas vinculadas à “[...] aquisição gratuita e automática de conhecimentos criados por outras empresas" (HIGACHI, 2006, p.75).

Ainda de acordo com Higachi (2006), a nova concepção teórica de tecnologia possibilita que modelos sejam formulados com progresso técnico endógeno, sendo o referencial sobre concorrência imperfeita utilizado para justificar investimentos privados em pesquisa e desenvolvimento tecnológico. Merece também realce a introdução de retornos crescentes à escala na produção do bem de consumo final, e de novos projetos de bens econômicos que são utilizados como forma de garantir que as oportunidades tecnológicas ocorram de forma ilimitada.

Além da abordagem vinculada à tradição neoclássica, Campos e Ruiz (2009) chamam a atenção para outras duas linhas de investigação sobre o processo de mudança tecnológica. A primeira está vinculada a abordagens da economia industrial, em que os processos inovativos e as mudanças tecnológicas resultam de características da estrutura de mercado, a exemplo da concentração e do tamanho das empresas em cada setor. Enquanto que a segunda linha de investigação refere-se a tradição evolucionista, a qual considera tanto elementos, lógica e sentido próprios para o processo de inovação, quanto fatores econômicos para sua concepção.

A respeito da teoria evolucionista, Nelson (2006) destaca a importância das aptidões organizacionais essenciais, que são moldadas pela estratégia e pela estrutura, ou seja, pelos compromissos assumidos e a forma de organização e condução das decisões. Para tanto, a teoria das aptidões dinâmicas considera que as empresas atuam em contexto schumpeteriano ou evolucionário, onde o sucesso ao longo do tempo vincula-se às “[...] aptidões para inovar e para tirar vantagem econômica da inovação” (NELSON, 2006, p. 182). Dentre os principais 
fatores que determinam e limitam as aptidões, especialmente vinculados a P\&D, destacam-se: a) habilidades, experiências e conhecimentos do pessoal de $\mathrm{P} \& \mathrm{D}$; b) natureza das equipes e dos procedimentos existentes para a formação de novos quadros; c) caráter dos processos de tomada de decisões e; d) produção e marketing, entre outros. Embora as aptidões de P\&D sejam consideradas as fontes mais importantes na dinâmica das empresas, Nelson (2006) destaca a importância e a articulação com outras aptidões dentro da empresa, que possibilitem uma conjuntura inovativa bem sucedida e lucrativa, conforme a argumentação de que:

[...] para uma empresa ser eficaz, é necessário que ela tenha uma estratégia razoavelmente coerente que defina e legitime, pelo menos em termos gerais, a maneira como a firma é organizada e governada, capacitando-a a enxergar as lacunas ou anomalias organizacionais, criando as bases para barganhar os recursos necessários para as aptidões essenciais que uma empresa precisa para poder avançar. (NELSON, 2006, p. 184).

No que concerne às trajetórias tecnológicas, Kim (2005, p.137) considera que as mesmas estão relacionadas à “[...] direção evolucionária do avanço tecnológico observável na indústria como um todo e nos diversos ramos industriais”. Para tanto, apresenta uma distinção entre as trajetórias tecnológicas em países avançados e em países que estão em processo de catching-up. Os primeiros transferem tecnologias para os países em desenvolvimento como uma estratégia global de negócios, enquanto que os segundos adquirem, assimilam e aperfeiçoam tecnologias estrangeiras. No caso dos países avançados, o autor chama a atenção para três estágios de desenvolvimento e variações da transformação tecnológica em ramos industriais e em empresas, discutidos por Abernathy e Utterback em 1978, a saber: 1) fluído; 2) transitório e; 3) específico. O primeiro marca o surgimento de tecnologias, com maior frequência para inovações radicais do que incrementais; o segundo é o momento da consolidação tecnológica, ocorrendo uma diminuição das inovações radicais e uma tendência para a consolidação e dominação de um produto e técnicas de produção; já no terceiro estágio, ocorre a maturidade da tecnologia, quando o processo inovativo desloca-se para melhorias incrementais e o processo competitivo torna-se mais vulnerável.

É no estágio específico (nas tecnologias maduras) da trajetória tecnológica dos países desenvolvidos que Kim (2005) considera que ocorre a transferência de ramos industriais para os países em desenvolvimento (ou em processo de catching-up), objetivando tanto o prolongamento do ciclo de vida de produtos e das tecnologias dos países desenvolvidos quanto o aproveitamento dos baixos custos de produção. Sendo assim, a trajetória tecnológica proposta para os países em desenvolvimento compreende: 1) aquisição; 2) assimilação e; 3) aperfeiçoamento. Ou seja, a aquisição de tecnologia estrangeira concentra-se em esforços de engenharia, sua assimilação se dá por meio da experiência adquirida no estágio de aquisição 
e, em alguns casos, o aperfeiçoamento ocorre via imitação em engenharia reversa para produção de bens diferenciados. Cabe ressaltar que a trajetória tecnológica dos países em processo de catching-up pode ocorre em estágios iniciais do desenvolvimento de inovações nos países avançados, e, por conseguinte, quanto mais próximo do estágio fluído, maior a probabilidade de os países em catching-up serem considerados desenvolvidos.

Nesse sentido, a liderança em tecnologias inovadoras ou imitativas depende do tamanho da empresa e, principalmente, de suas competências acumuladas, assim sendo, a trajetória tecnológica é determinada pela atividade principal realizada e acumulada no passado. Acrescenta-se a isso o fato de que a função técnica em grandes empresas deve compreender limites adequados para exploração de novas oportunidades, novas formas de aprendizagem corporativa e formação de expectativas tecnológicas que estimulem a alocação de recursos em P\&D (PAVITT, 1984; 1994).

Pavitt (1984) apresenta uma discussão sobre os padrões setoriais de mudança técnica, considerando as semelhanças e diferenças na natureza das fontes, os setores e os impactos das inovações. O autor considera que a produção, inovação e disseminação de inovações técnicas são elementos essenciais para o processo de desenvolvimento econômico e mudança social, assim como considera que a inovação técnica apresenta a característica distintiva para a competição entre produtos e indústrias. Por conseguinte, os setores variam a partir da importância relativa de inovações (de produtos e processos) em fontes de tecnologia, no tamanho e nos padrões de diversificação tecnológica das firmas inovadoras. Portanto, diferentes atividades principais geram diferentes trajetórias tecnológicas.

A partir da observação das semelhanças nos processos produtivos e, consequentemente, nas trajetórias tecnológicas de empresas e setores diversos, Pavitt (1984) propõe a classificação de setores e indústrias em três taxonomias, a saber:

1) dominados por fornecedores: corresponde, em geral, a setores tradicionais, pequenos e com baixa capacidade interna de impulsionar P\&D. Neste sentido, as inovações vêm de fornecedores de equipamentos e materiais, assim como via aprendizado informal direcionado para a assimilação de tecnologias externas;

2) produção intensiva: vincula-se à produção em massa, de grande escala e/ou de linhas de montagem. Apresenta como mecanismos principais o processo de divisão do trabalho, substituição de máquinas que leva a um aumento do tamanho do mercado e redução de custos de produção, assim como atribui destaque ao setor de engenharia de produção. Essa taxonomia subdivide-se em intensivos em escala e em fornecedores especializados. Nos setores intensivos em economias de escala, observa-se considerável esforço inovador, sendo 
parte da tecnologia realizada internamente. E nos setores com fornecedores especializados, ocorre uma interação e complementaridade tecnológica através de indústrias de peças, componentes e acessórios;

3) baseados na ciência: chama-se a atenção para a importância do técnico que observa, combina elementos e cria inovações. Além disso, apresentam-se como os setores com maiores oportunidades tecnológicas, em que as áreas de P\&D são o foco de atenção e configuram-se como meio principal de aprendizado. Nestes setores observa-se também a interação com outros centros de pesquisa (PAVITT, 1984; CAMPOS; RUIZ, 2009). No Quadro 1, apresenta-se uma sistematização das características, das inovações e de exemplos para cada taxonomia.

Quadro 1 - Taxonomia de padrões setoriais e mudança técnica: características e inovações

\begin{tabular}{|c|c|c|c|c|}
\hline \multicolumn{2}{|c|}{$\begin{array}{c}\text { Categorias de } \\
\text { indústrias/setores }\end{array}$} & Características & Inovações & Exemplos \\
\hline \multicolumn{2}{|c|}{$\begin{array}{l}\text { Dominados por } \\
\text { fornecedores }\end{array}$} & $\begin{array}{l}\text { Indústrias pequenas e com pouca } \\
\text { atenção para os departamentos de } \\
\text { P\&D }\end{array}$ & $\begin{array}{l}\text { Predominância de } \\
\text { inovações de } \\
\text { processo }\end{array}$ & $\begin{array}{l}\text { Indústrias têxteis, } \\
\text { madeireiras, gráficas, } \\
\text { confecções, calçados, } \\
\text { dentre outras }\end{array}$ \\
\hline \multirow{2}{*}{ 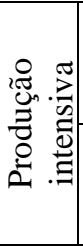 } & $\begin{array}{l}\text { Intensivos em } \\
\text { escala }\end{array}$ & $\begin{array}{l}\text { Indústrias fabricantes de bens } \\
\text { duráveis }\end{array}$ & $\begin{array}{l}\text { Inovações tanto em } \\
\text { processo quanto em } \\
\text { produtos }\end{array}$ & $\begin{array}{l}\text { Indústria automotiva, } \\
\text { siderúrgica, dentre } \\
\text { outras. }\end{array}$ \\
\hline & $\begin{array}{l}\text { Fornecedores } \\
\text { especializados }\end{array}$ & $\begin{array}{l}\text { Indústrias de pequeno e médio porte, } \\
\text { especializadas no fornecimento de } \\
\text { insumos para indústrias maiores }\end{array}$ & $\begin{array}{l}\text { Inovações em } \\
\text { produtos }\end{array}$ & $\begin{array}{l}\text { Indústrias mecânicas, } \\
\text { de maquinaria e } \\
\text { instrumentos }\end{array}$ \\
\hline \multicolumn{2}{|c|}{ Baseados na ciência } & $\begin{array}{l}\text { Sensíveis à progressos de } \\
\text { conhecimento científico }\end{array}$ & $\begin{array}{l}\text { Inovações tanto em } \\
\text { processo quanto em } \\
\text { produtos }\end{array}$ & $\begin{array}{l}\text { Indústrias químicas, } \\
\text { farmacêutica e } \\
\text { microeletrônica }\end{array}$ \\
\hline
\end{tabular}

Fonte: elaboração dos autores, com base em Pavitt (1984; 1994) e em Campos e Ruiz (2009)

A compreensão das regularidades e comportamentos setoriais vinculados à inovação tem possibilitado a ampliação de estudos e orientações para políticas tecnológicas e, “[...] apesar do seu caráter estático, é possível realizar análise de estática comparativa, a fim de observar mudanças nas formas relevantes de inovação setorial ou evidenciar formas novas" (CAMPOS; RUIZ, 2009, p.171).

Por fim, cabe destacar o fato de que as diferentes categorias de firmas se excedem e geram um fluxo tecnológico que emergem de outras. Ou seja, as empresas fornecedoras dominadas obtêm parte de sua tecnologia de empresas de produção intensiva e de base científica; as empresas de base científica transferem tecnologia para as empresas intensivas de produção; e as empresas de base científica e de produção intensiva tanto recebem quanto fornecem tecnologia para fornecedores especializados de equipamentos de produção. Assim sendo, as ligações tecnológicas entre os setores vão além de transações comerciais de produtos que incorporam a tecnologia, e incluem fluxos de informações e habilidades 
específicas, configurando-se como essenciais para impulsionar o processo de mudança técnica e levar a diversificação da trajetória tecnológica (PAVITT, 1984).

\section{Processos e estímulos inovativos no setor automotivo brasileiro}

A indústria automotiva possui forte influência e impactos em uma economia, tanto pelo elevado peso do valor agregado de seus produtos na transformação econômica, quanto pelo conjunto de influências que o setor exerce em políticas econômicas nacionais e internacionais. Soma-se a isso a grande capacidade de encadeamento produtivo sobre outros setores econômicos, em que seu desempenho afeta diretamente a produção de diversos setores da indústria (DE NEGRI et al., 2008).

É um setor tipicamente oligopolístico, formado, quase que exclusivamente, por grandes empresas privadas de origem estrangeira instaladas em países diversos. No contexto internacional, sua influência em políticas econômicas concentra-se, em geral, em acordos bilaterais ou de blocos econômicos para comercialização de seus produtos, redução de tarifas e transferência de tecnologia (equipamentos, padrões de inovação tecnológica e organizacional, e gestão da força de trabalho, por exemplo). Enquanto que, em nível nacional, além do conjunto de políticas de estímulo e incentivos fiscais, o setor automotivo também exerce influência na criação de regulações federais, regionais e locais (KIM, 2005).

O Estado desempenha um importante papel ao regular, estimular e facilitar a implementação e maturação do setor em regiões estratégias, a partir de um conjunto de medidas (isenção tarifária, concessões financeiras e proteção ao mercado interno, entre outras) que compreendem as políticas de desenvolvimento industrial do país. Ao indicar o importante papel que o Estado exerce, tanto na capacidade de assumir riscos quanto na sua capacidade empreendedora e de financiamento de grandes projetos industriais e de inovação, Mazzucato (2014) chama a atenção para um novo posicionamento que o Estado deve assumir junto à iniciativa privada - o de incentivador dos setores -, criando um sistema que estimule investimentos privados no médio e no longo prazo.

A inovação tem, cada vez mais, se caracterizado como um elemento determinante do processo competitivo na indústria automotiva, atrelado às mudanças organizacionais e principalmente tecnológicas, que também implicam em interações com diversos fornecedores em uma cadeia produtiva. Estas interações envolvem setores produtivos como os de aço e derivados, material eletrônico, máquinas e equipamentos, produtos de metal e artigos de borracha e plástico, que se apresentam como importantes fornecedores para os elos finais da 
cadeia automotiva (automóveis, caminhonetas e utilitários, bem como caminhões e ônibus) (CARVALHO, 2008; DE NEGRI et al., 2008; BAHIA; DOMINGUES, 2010).

De acordo com Bahia e Domingues (2010), a cadeia automotiva configura-se como uma das mais importantes na economia brasileira, estando isso relacionado ao fato de que seu desempenho pode afetar, direta e indiretamente, diversos setores econômicos. Portanto, é uma cadeia determinante para o crescimento do produto interno bruto do país, aspecto corroborado pelo fato de que, no pós década de 1960, os ciclos da economia brasileira iniciam-se e têm como foco os setores de bens de consumo duráveis, especialmente nas estratégias de desenvolvimento da cadeia automotiva no país.

A partir dessas considerações sobre a importância e o peso da cadeia automotiva para a economia brasileira, cabe fazer uma breve menção ao processo de reestruturação pelo qual o setor passou nas últimas décadas. No cenário mundial, destaca-se a passagem da produção artesanal (no século XIX) para a produção em massa (no início do século XX). Essa transição foi possível graças a Henry Ford e sua incorporação de "inovações básicas" na linha de montagem da Ford, ou seja, trata-se de inovações organizacionais, técnicas e sociais que possibilitaram a redução dos custos e do preço do modelo desenvolvido no período, o Modelo T. Soma-se a isso a dominação do motor a combustão interna nos anos 1920, frente à máquina a vapor e ao motor elétrico, assim como o desenvolvimento da intercambialidade de peças. De acordo com Freeman e Soete (2008), os ganhos de escala na produção decorrentes de custos e preços decrescentes provocaram uma verdadeira revolução na economia e nas técnicas de administração, induzindo ao sistema de produção em massa. Neste contexto, o fordismo surge vinculado à alta mecanização da produção, linhas de montagens móveis, altos salários (para combater a alta rotatividade), elevada produtividade e preços baixos dos produtos.

O sistema de produção em massa também foi acompanhado por problemas relacionados a peças defeituosas. Este foi um elemento central pelo qual os produtores japoneses, no pós Segunda Guerra Mundial, confrontaram o sistema fordista via redução de subsistemas e peças defeituosas. A utilização e as experiências com a engenharia reversa também contribuíram para o foco na alta qualidade dos produtos e da tecnologia japonesa. Mesmo que as firmas japonesas não tenham realizado grandes inovações radicais nos produtos, suas inovações incrementais e a capacidade de redesenhar projetos e processos foram fatores chaves para a vantagem competitiva alcançada, especialmente vinculada aos ganhos de produtividade e de qualidade. Com o surgimento do sistema de produção enxuta da Toyota, introduziram-se novas práticas para produção de automóveis: redução de desperdícios, mais responsabilidades aos trabalhadores na linha de produção, transferência de responsabilidades para equipes de 
produção, relação de proximidade com os fornecedores (por meio do chamado just-in-time, uma nova configuração de organização e coordenação dos fluxos de fornecimento de peças, eliminando especialmente os estoques e dinamizando o tempo), assim como o estímulo à discussão sobre os processos e produtos entre engenheiros e trabalhadores (FREEMAN; SOETE, 2008).

Cabe chamar a atenção para as mudanças significativas que o sistema just-in-time proporcionou no relacionamento entre empresas montadoras de veículos e empresas fornecedoras (ou as chamadas sistemistas). Por um lado, o sistema estabelece uma maior dependência às empresas fornecedoras, um maior compartilhamento de riscos e uma comunicação mais complexa e constante entre montadoras e fornecedores, por outro lado, exige das empresas fornecedoras uma maior qualidade nos componentes fornecidos e uma adequação aos novos projetos e inovações das montadoras. Conforme destacado por Freeman e Soete (2008):

Uma considerável responsabilidade na elaboração dos projetos de subsistemas foi atribuída aos fornecedores de primeira linha, que foram obrigados a se adequar a determinadas especificações de performance. Cada fornecedor de primeira linha organizou seus próprios fornecedores de segunda linha para componentes mais simples. (FREEMAN; SOETE, 2008, p. 270).

Esse tipo de dinâmica no fornecimento de peças e acessórios foi observado na organização das plantas industriais da Fiat Chrysler Automobiles (FCA), em Goiana-PE, e na Renault no Brasil, em São José dos Pinhais-PR ${ }^{3}$. No que se refere à FCA, parte das empresas sistemistas se instalaram na mesma planta industrial da montadora, enquanto que no caso da Renault as empresas estão instaladas na região metropolitana de Curitiba-PR e nas proximidades da montadora. Ainda no que se refere ao caso da Renault, uma dinâmica também mencionada em visita técnica corresponde ao Material Requiment Planning (MRP), que, através da difusão de sistemas computacionais e do uso de softwares, permite à montadora coordenar a entrada de peças e acessórios e estabelecer um maior controle e comunicação com os seus fornecedores.

No que concerne ao cenário nacional, Barros e Pedro (2012) destacam a importância da criação do Banco Nacional de Desenvolvimento Econômico e Social (BNDES), para estímulo

\footnotetext{
${ }^{3}$ As visitas técnicas ocorreram em momentos diferentes como forma de contribuição para as discussões sobre a temática, seja em grupos de pesquisas seja em disciplinas da pós-graduação. No caso da Fiat Chrysler Automobiles (FCA), as visitas ocorreram ao longo do ano de 2015, através do Laboratório de Estudos e Pesquisas em Políticas Públicas e Trabalho (LAEPT), da Universidade Federal da Paraíba (UFPB). Enquanto que no caso da Renault no Brasil, a visita ocorreu no segundo semestre de 2016, a partir de discussões no âmbito da disciplina de Concorrência e Inovação, do Programa de Pós-Graduação em Políticas Públicas da Universidade Federal do Paraná (UFPR).
} 
ao desenvolvimento da indústria automotiva nacional, e a priorização de políticas direcionadas para o desenvolvimento de inovações tecnológicas.

A instalação das primeiras indústrias de montagem de veículos no Brasil ocorreu no início do século $\mathrm{XX}^{4}$. Até a primeira metade do mesmo século, as empresas instaladas dedicaram-se à montagem de peças e veículos importados. Foi a partir do segundo governo de Getúlio Vargas (1951-54), e com maior intensidade no Plano de Metas ${ }^{5}$, de Juscelino Kubitschek (1956-61), que se observaram os primeiros modelos nacionalizados de veículos, impulsionados tanto pela gradual proibição de importação de autopeças com similar nacional e de importação de veículos completos, quanto pelos incentivos governamentais e financiamentos do BNDES. Nos governos subsequentes, mais especificamente durante o período do milagre econômico (1969-1973), a produção e venda de veículos cresceu substancialmente, contudo, o setor automobilístico deixou de ser prioridade específica na política industrial e passou a ser contemplado com políticas gerais do setor industrial (CAPUTO; MELO, 2009; LACERDA, 2010a; LACERDA, 2010b; BARROS; PEDRO, 2012).

A partir dos choques do petróleo dos anos 1970 e durante a década de 1980 (a chamada década perdida da economia), as vendas de carros sofrem uma queda acentuada, atrelada à restrição de crédito, crise da dívida externa e falta de investimentos, tendo a política econômica se direcionado para o controle da inflação. O BNDES desempenhou um papel importante desde a sua criação, na década de 1950, até fins da década de 1970, com estímulos e incentivos à comercialização de autopeças no exterior, incentivos à pesquisa e fomento das empresas de capital nacional. Entretanto, “[...] as medidas não estavam inseridas em um planejamento estratégico de longo prazo e, apesar de relevantes, não tiveram continuidade e eram sensíveis às alterações de governo" (BARROS; PEDRO, 2012, p. 107).

Na década de 1990, com a gradual abertura comercial, o setor automotivo volta a ser foco de políticas industriais especificas ${ }^{6}$, sendo motivadas especialmente pelos baixos investimentos no setor durante a década anterior. De acordo com Barros e Pedro (2012, p. 107), estes baixos investimentos contribuíram para vários problemas na cadeia automotiva,

\footnotetext{
${ }^{4}$ As primeiras montadoras multinacionais a se instalar no Brasil foram: Ford Motor (1919), General Motors (1925) e Fiat (1928). (CAPUTO; MELO, 2009; BARROS; PEDRO, 2012).

${ }^{5} \mathrm{~A}$ consolidação da indústria automobilística brasileira fazia parte do conjunto de metas do planejamento estratégico do governo de Juscelino Kubitschek, sendo conduzido pelo Grupo Executivo da Indústria Automobilística (GEIA), criado em 1956 (CAPUTO; MELO, 2009; BARROS; PEDRO, 2012).

${ }^{6}$ Em 1995, por exemplo, foi instituído o Regime Automotivo Brasileiro (Medida Provisória 1024/95), visando: a modernização do setor, elevação do investimento e expansão da competitividade externa. Além disso, "[...] abrangeu incentivos fiscais para as empresas que decidissem se instalar no Brasil e incentivos diferenciados para aquelas que optassem por implantar fábricas nas regiões menos desenvolvidas.” (BARROS; PEDRO, 2012, p. 108).
} 
"[...] com destaque para a reduzida automação e eficiência, a falta de competitividade internacional pela fabricação de modelos defasados tecnologicamente e os altos custos de produção". Sendo assim, tanto a abertura comercial quanto as políticas governamentais proporcionaram mudanças significativas, com progressiva elevação da concorrência, evolução tecnológica (a partir do maior contato com a tecnologia externa), ganhos de produtividade, capacidade produtiva e crescimento do mercado interno.

A partir do início dos anos 2000, observa-se uma mudança expressiva nos financiamentos governamentais para o setor automotivo, que passaram a estimular o desenvolvimento de inovações tecnológicas. Isso induz à adequação que o setor interno deve realizar para a nova agenda da indústria automobilística, necessitando de um redirecionamento das políticas públicas para uma estratégia de planejamento de longo prazo. Sendo assim, a concorrência passa a pressupor fundamentalmente a inovação como elemento dinâmico e essencial na cadeia automotiva, como bem argumentado por Barros e Pedro (2012), ao apresentarem um panorama da nova agenda para o setor, na qual

\footnotetext{
Novos conceitos passaram a ser considerados estratégicos e essenciais para a indústria, como o desenvolvimento tecnológico contínuo, investimentos em engenharia automotiva e a adequação dos veículos a requisitos ambientais e de segurança. O desenvolvimento dos veículos passou a ser global, envolvendo engenharia compartilhada entre filiais de diversos países e a matriz. A busca por novas tecnologias passou a ser muito relevante, e a inovação tornou-se prioridade para o desenvolvimento das empresas. A fabricação de veículos híbridos e elétricos, ainda que incipiente, já é realidade em diversos mercados, o que iniciou uma corrida tecnológica entre os principais players do setor. (BARROS; PEDRO, 2012, p. 114$115)$.
}

Neste contexto, o Quadro 2 apresenta os principais meios de financiamento à inovação do BNDES para a cadeia automotiva, evidenciando o redirecionamento das políticas públicas para o setor a partir dos anos 2000. Diversas alterações são observadas nos programas e linhas de inovação, mas com poucas mudanças em seu conteúdo. Pela análise dos programas e linhas de financiamento à inovação do BNDES, percebe-se que o elemento inovação compreende tanto mudanças incrementais (a exemplo de aprimoramentos em design, mecânica e desempenho de veículos) quanto mudanças radicais que alteram a trajetória tecnológica dos produtos e/ou processos, que, por conseguinte, envolvem elevado risco tecnológico. No curto prazo, as mudanças tecnológicas incrementais são mais utilizadas na produção de veículos, tornando o setor mais competitivo. Contudo, a tendência e o surgimento de novas rotas tecnológicas requerem, cada vez mais, uma articulação e planejamento de longo prazo entre as empresas da cadeia automotiva e as políticas governamentais. 
Quadro 2 - Principais meios de financiamento à inovação do BNDES

\begin{tabular}{|c|c|c|}
\hline $\begin{array}{l}\text { Programas e linhas } \\
\text { de financiamento }\end{array}$ & Objetivos & Observações \\
\hline $\begin{array}{l}\text { Linha Inovação } \\
\text { PD\&I* }\end{array}$ & $\begin{array}{l}\text { Apoiar projetos de pesquisa, desenvolvimento tecnológico e } \\
\text { inovação (relacionados a novos produtos e processos) }\end{array}$ & Vigente de 2006 a 2008 \\
\hline $\begin{array}{l}\text { Linha Inovação } \\
\text { Produção }\end{array}$ & $\begin{array}{l}\text { Apoiar inovações incrementais (relacionados a produtos e } \\
\text { processos), formação de capacitações e ambientes } \\
\text { inovadores, assim como para criação, adequação e/ou } \\
\text { expansão de capacidade para comercialização de resultados } \\
\text { de processos inovativos }\end{array}$ & $\begin{array}{l}\text { Vigente de } 2006 \text { a } \\
2008, \text { sendo recriada } \\
\text { em } 2009\end{array}$ \\
\hline $\begin{array}{l}\text { Programa de Apoio à } \\
\text { Engenharia } \\
\text { Automotiva }\end{array}$ & $\begin{array}{l}\text { Fortalecer áreas de engenharia de empresas vinculadas ao } \\
\text { setor automotivo, através de competências e } \\
\text { desenvolvimento técnico }\end{array}$ & Vigente de 2007 a 2009 \\
\hline $\begin{array}{l}\text { Inovação } \\
\text { Tecnológica }\end{array}$ & $\begin{array}{l}\text { Apoiar projetos de pesquisa, desenvolvimento ou inovação } \\
\text { (relacionados a novos ou aprimorados produtos e processos, } \\
\text { com significativo risco tecnológico) }\end{array}$ & $\begin{array}{lcr}\text { Substituiu } & \text { a } & \text { Linha } \\
\text { Inovação } & \text { PD\&I, em } \\
2008 & \end{array}$ \\
\hline Capital Inovador & $\begin{array}{l}\text { Apoiar os esforços inovativos relacionados à infraestrutura } \\
\text { física e ativos tangíveis e intangíveis, assim como a parques } \\
\text { tecnológicos e incubadoras }\end{array}$ & $\begin{array}{l}\text { Substituiu a Linha } \\
\text { Inovação Produção, em } \\
2008\end{array}$ \\
\hline $\begin{array}{l}\text { BNDES } \\
\text { Proengenharia }\end{array}$ & $\begin{array}{l}\text { Ampliação de financiamento para outros setores, além do } \\
\text { automotivo, a exemplo de bens de capital, aeronáutica, } \\
\text { defesa, aeroespacial, nuclear, assim como a cadeia de } \\
\text { fornecedores das indústrias de petróleo e gás }\end{array}$ & $\begin{array}{l}\text { Substituiu o Programa } \\
\text { de Apoio à Engenharia } \\
\text { Automotiva, em } 2009\end{array}$ \\
\hline
\end{tabular}

Todos esses meios de financiamento contribuíram significativamente para o estímulo à inovação na cadeia automotiva. Cabe fazer menção ao BNDES Proengenharia, que a partir da segunda metade da década de 2000 financiou vários projetos de empresas sistemistas e fabricantes de veículos instalados no país, contribuindo para elevar a competição entre companhias. Exemplos desses projetos estiveram ligados “[...] à reestilização de veículos, o desenvolvimento de novos motores para veículos pesados adequados às exigências da legislação ambiental, bem como a implantação, a ampliação e a modernização de centros de engenharia nas empresas produtoras de veículos e autopeças.” (BARROS; PEDRO, 2012, p. 119).

No que se refere às possíveis rotas tecnológicas para o setor automotivo, Barros e Pedro (2012, p. 120) consideram que “[...] em médio e longo prazos, o apoio a novos modelos de tração híbrida e elétrica, ao desenvolvimento de baterias, a sistemas de automatização integrados e ao uso de combustíveis alternativos deve se tornar imprescindível à indústria". Assim sendo, tanto a participação dos financiamentos do BNDES e o ambiente macroeconômico (política industrial, de ciência e tecnologia, de comércio, monetária e educacional), quanto à integração com fontes nacionais de tecnologia (institutos e centros de pesquisa, universidades e outros sistemas de apoio), fazem-se cada vez mais necessários para o estímulo ao desenvolvimento de inovações que envolvem um elevado risco e mudanças na trajetória tecnológica (KIM, 2005). 
A discussão das rotas tecnológicas para o setor automobilístico brasileiro ganha ênfase, especialmente, devido ao crescimento da economia e do mercado doméstico nos últimos anos, com ascensão da classe média e do salário mínimo real, assim como a tendência para a estagnação de mercados desenvolvidos, o que abre espaço para o crescimento da participação dos países em desenvolvimento na produção de veículos (BARROS; PEDRO, 2012), conforme evidenciado na tabela 1 .

No que concerne à participação dos países emergentes na produção mundial de automóveis, cabe fazer menção à ampliação da sua participação nos últimos anos, um exemplo do que foi o crescimento de $157 \%$ entre 2002 e 2016, conforme a tabela 1 . Destaque especial é atribuído à forte inserção e participação da produção de automóveis da China, Índia e países do Leste Europeu, que apresentam taxas de crescimento, para o período em análise, de $756 \%, 402 \%$ e $192 \%$, respectivamente. O bom desempenho dos países emergentes está relacionado ao padrão de consumo direcionado para a produção de carros baratos. Outro elemento que também corrobora para esses resultados tem sido a penetração de montadoras nessas economias, visando especialmente o crescimento potencial de seus mercados.

É importante também destacar que os demais países emergentes, selecionados na Tabela 1, seguem uma mesma tendência histórica de ampliação do desempenho dos dois principais players (China e Índica) na participação na produção mundial de veículos, embora em dimensões menores. Para o período de 2002 a 2016, destaca-se o crescimento de alguns países do leste europeu, a exemplo de Eslováquia, Romênia, Hungria, República Tcheca e Polônia, com taxas de crescimento de $361 \%, 352 \%, 334 \%, 202 \%$ e $119 \%$, respectivamente. Ainda que México e Brasil tenham apresentado taxas de crescimentos inferiores, 99\% e 20\%, respectivamente, cabe destacar seus significativo peso e participação na produção mundial de veículos, com produções equivalentes a 3,6 milhões de autoveículos no México e 2,16 milhões no Brasil, em 2016. 
Tabela 1 - Produção de autoveículos em países emergentes selecionados - 2002 a 2016 (em milhões de unidades)

\begin{tabular}{|c|c|c|c|c|c|c|c|c|c|c|c|c|c|c|c|}
\hline & 2002 & 2003 & 2004 & 2005 & 2006 & 2007 & 2008 & 2009 & 2010 & 2011 & 2012 & 2013 & 2014 & 2015 & 2016 \\
\hline Argentina & 0,16 & 0,17 & 0,26 & 0,32 & 0,43 & 0,54 & 0,60 & 0,51 & 0,72 & 0,83 & 0,76 & 0,79 & 0,62 & 0,53 & 0,47 \\
\hline Brasil & 1,79 & 1,83 & 2,32 & 2,53 & 2,61 & 2,98 & 3,22 & 3,18 & 3,38 & 3,41 & 3,40 & 3,71 & 3,15 & 2,43 & 2,16 \\
\hline China & 3,29 & 4,44 & 5,23 & 5,72 & 7,19 & 8,88 & 9,30 & 13,79 & 18,26 & 18,42 & 19,27 & 22,12 & 23,73 & 24,50 & 28,12 \\
\hline Índia & 0,89 & 1,16 & 1,51 & 1,64 & 2,02 & 2,25 & 2,33 & 2,64 & 3,56 & 3,93 & 4,17 & 3,90 & 3,84 & 4,13 & 4,49 \\
\hline México & 1,80 & 1,58 & 1,58 & 1,68 & 2,05 & 2,10 & 2,17 & 1,56 & 2,34 & 2,68 & 3,00 & 3,05 & 3,37 & 3,57 & 3,60 \\
\hline Rússia & 1,22 & 1,28 & 1,39 & 1,35 & 1,51 & 1,66 & 1,79 & 0,73 & 1,40 & 1,99 & 2,23 & 2,19 & 1,89 & 1,38 & 1,30 \\
\hline Tailândia & 0,58 & 0,74 & 0,93 & 1,12 & 1,19 & 1,29 & 1,39 & 1,00 & 1,64 & 1,46 & 2,43 & 2,46 & 1,88 & 1,92 & 1,94 \\
\hline $\begin{array}{l}\text { Leste } \\
\text { Europeu* }\end{array}$ & 1,39 & 1,49 & 1,84 & 2,17 & 2,71 & 3,44 & 3,69 & 3,12 & 3,15 & 3,51 & 3,52 & 3,57 & 3,79 & 3,99 & 4,04 \\
\hline $\begin{array}{l}\text { República } \\
\text { Tcheca }\end{array}$ & 0,45 & 0,44 & 0,45 & 0,60 & 0,85 & 0,94 & 0,95 & 0,98 & 1,08 & 1,20 & 1,18 & 1,13 & 1,25 & 1,30 & 1,35 \\
\hline Hungria & 0,14 & 0,13 & 0,12 & 0,15 & 0,19 & 0,29 & 0,35 & 0,21 & 0,21 & 0,21 & 0,22 & 0,32 & 0,44 & 0,50 & 0,47 \\
\hline Polônia & 0,31 & 0,32 & 0,60 & 0,61 & 0,71 & 0,79 & 0,95 & 0,88 & 0,87 & 0,84 & 0,65 & 0,59 & 0,59 & 0,66 & 0,68 \\
\hline Romênia & 0,08 & 0,10 & 0,12 & 0,19 & 0,21 & 0,24 & 0,25 & 0,30 & 0,35 & 0,34 & 0,34 & 0,41 & 0,39 & 0,39 & 0,36 \\
\hline Eslováquia & 0,23 & 0,28 & 0,22 & 0,22 & 0,30 & 0,57 & 0,58 & 0,46 & 0,56 & 0,64 & 0,93 & 0,98 & 0,97 & 1,00 & 1,04 \\
\hline Eslovênia & 0,13 & 0,12 & 0,13 & 0,18 & 0,15 & 0,20 & 0,20 & 0,21 & 0,00 & 0,17 & 0,13 & 0,09 & 0,12 & 0,13 & 0,13 \\
\hline Ucrânia & 0,05 & 0,11 & 0,19 & 0,22 & 0,30 & 0,40 & 0,42 & 0,07 & 0,08 & 0,10 & 0,08 & 0,05 & 0,03 & 0,01 & 0,01 \\
\hline $\begin{array}{l}\text { Total } \\
\text { Emergentes }\end{array}$ & 11,13 & 12,69 & 15,05 & 16,54 & 19,71 & 23,14 & 24,48 & 26,53 & 34,46 & 36,22 & 38,80 & 41,80 & 42,27 & 42,45 & 46,12 \\
\hline $\begin{array}{l}\text { Total } \\
\text { Mundial }\end{array}$ & 58,99 & 60,66 & 64,50 & 66,72 & 69,22 & 73,27 & 70,73 & 61,76 & 77,58 & 79,88 & 84,24 & 87,60 & 89,78 & 90,78 & 94,98 \\
\hline $\begin{array}{l}\text { Participação } \\
\text { \% países } \\
\text { emergentes } \\
\text { na produção } \\
\text { mundial }\end{array}$ & 18,9 & 20,9 & 23,3 & 24,8 & 28,5 & 31,6 & 34,6 & 43,0 & 44,4 & 45,3 & 46,1 & 47,7 & 47,1 & 46,8 & 48,6 \\
\hline
\end{tabular}

Fonte: elaboração dos autores, com base em dados da Organisation Internationale des Constructeurs d'Automobiles - OICA (2017)

* Países do Leste Europeu produtores de veículos automotores (República Tcheca, Hungria, Polônia, Romênia, Eslováquia, Eslovênia e Ucrânia), exceto Rússia

Nota: Autoveículos compreende automóveis, comerciais leves, caminhões e ônibus

Por fim, o Quadro 3 sintetiza as principais e possíveis rotas tecnológicas para o setor automotivo. A discussão das principais tendências e rotas tecnológicas vinculadas à inovação de produtos e processos na cadeia automotiva tanto confirma a importância de políticas públicas de financiamento para o desenvolvimento e estímulo à inovação do setor, quanto aponta a demanda por aprimoramentos dos atuais meios de financiamento e pela criação de novos. 


\section{Quadro 3 - Principais rotas tecnológicas para o setor automotivo}

\begin{tabular}{|c|c|}
\hline $\begin{array}{l}\text { Tendências } \\
\text { tecnológicas }\end{array}$ & Aspectos principais \\
\hline $\begin{array}{l}\text { Eletromobilidade } \\
\text { (ou a migração } \\
\text { para tecnologia dos } \\
\text { veículos elétricos) }\end{array}$ & $\begin{array}{l}\text { Tem ganhado destaque devido à discussão e percepção das questões ambientais na } \\
\text { sociedade contemporânea, onde o veículo a combustão não tem contribuído para a } \\
\text { redução da emissão de poluentes. }\end{array}$ \\
\hline Hibridização & $\begin{array}{l}\text { Existem autores que apontam para a importância da produção de veículos híbridos, antes } \\
\text { da difusão da tecnologia de veículos elétricos. Os argumentos se sustentam devido ao } \\
\text { custo da bateria e do motor elétrico (sendo inferiores no veículo híbrido), assim como a } \\
\text { baixa autonomia da bateria e da infraestrutura de recarga para veículos totalmente } \\
\text { elétricos. Sendo assim, a produção de veículos híbridos combinaria tecnologias a } \\
\text { combustão e elétrica. Dentre outras questões, a discussão que se coloca para a difusão de } \\
\text { veículos elétricos está relacionada ao padrão de bateria, durabilidade, custo e } \\
\text { infraestrutura de recarga. }\end{array}$ \\
\hline $\begin{array}{l}\text { Flex fuel e } \\
\text { biocombustíveis }\end{array}$ & $\begin{array}{l}\text { A produção de carros flexfuel tem possibilitado maior flexibilidade quanto ao } \\
\text { abastecimento (gasolina, etanol ou combinação dos dois combustíveis), assim como } \\
\text { apresenta-se como um modelo mais sustentável ambientalmente, quando comparado a } \\
\text { veículos movidos por combustíveis fósseis. Contudo, os veículos flex ainda apresentam } \\
\text { menor eficiência, abrindo espaço para aprimoramentos tecnológicos em seus motores } \\
\text { para aumento da eficiência energética. }\end{array}$ \\
\hline $\begin{array}{l}\text { Modificações no } \\
\text { conceito de } \\
\text { transporte urbano }\end{array}$ & $\begin{array}{l}\text { Redução de peso e tamanho, conceitos mais amplos de sustentabilidade, crescimento da } \\
\text { eletrônica utilizada, produção de ônibus inteligentes, motocicletas elétricas, são todos } \\
\text { aspectos que os veículos urbanos tendem a incorporar cada vez mais. Destaca-se que } \\
\text { além de problemas de engarrafamento das cidades, os veículos mais leves são mais } \\
\text { econômicos. }\end{array}$ \\
\hline
\end{tabular}

Fonte: elaboração dos autores, com base em Barros e Pedro (2012)

Questões como a sustentabilidade ambiental na sociedade contemporânea e as modificações e tendências tecnológicas atreladas à concorrência inerente ao processo inovativo do setor automotivo, são elementos que podem alterar significativamente toda a estrutura da indústria automobilística. Neste contexto, o estímulo a pesquisa e desenvolvimento são essenciais para o potencial de novas tecnologias ligadas a eletromobilidade, hibridização, combustíveis alternativos e nanotecnologia. Esta última configura-se como uma oportunidade tecnológica que pode contribuir tanto para aperfeiçoamentos no produto (funcionalidade e design de peças) quanto para melhorias de processos.

Com base na discussão realizada nesta subseção, e levando-se em consideração a taxonomia para as empresas apresentada por Pavitt, percebe-se que, embora o setor automotivo esteja classificado enquanto produção intensiva, o mesmo mostra-se também fortemente interligado com outras categorias. Ou seja, há um fluxo tecnológico que emerge das demais categorias, mais especificamente dos setores baseados na ciência. Este tipo de ligação tecnológica existente entre setores configura-se como essencial para estimular o processo de mudança tecnológica, podendo envolver fluxos de informações e de habilidades específicas. 


\section{Considerações finais}

O presente trabalho buscou apresentar uma discussão sobre padrões setoriais de mudança técnica, tecnologia e dinâmicas industriais a partir da observação dos processos de inovação na indústria automobilística brasileira. Além disso, procurou-se destacar as trajetórias e rotas tecnológicas para o setor em questão e a importância de políticas públicas governamentais para o fomento e a disseminação de inovações em setores considerados estratégicos para o país. Toda essa discussão pressupôs, fundamentalmente, a inovação enquanto elemento central e determinante da concorrência. Enquanto elemento analítico, considerou-se a classificação da taxonomia para as indústrias ou setores de Pavitt (1984), a saber: 1) dominados por fornecedores; 2) produção intensiva e; 3) baseados na ciência.

A partir da discussão das características do setor automotivo brasileiro, ficam evidentes as mudanças organizacionais, estruturais e, mais recentemente, o foco no desenvolvimento de tecnologias e inovações. Durante o século $\mathrm{XX}$, observa-se uma indústria voltada para montagem de partes e peças importadas, tentativas de nacionalização de peças e uma descontinuidade das políticas indústrias para o setor automotivo, com foco na implantação da indústria pesada, especialmente após a década de 1960. O surgimento de um novo paradigma produtivo mundial, desenvolvido por empresas japonesas, o sistema toyotista, possibilitou a criação de partes e módulos no processo produtivo a partir de uma forte troca de informações e integração com as empresas fornecedoras (ou sistemistas), nos elos da linha de montagem.

Com o fortalecimento das empresas sistemistas dentro da cadeia automotiva, o processo de desenvolvimento de inovações para o setor tende a se ampliar além do escopo das empresas montadoras (matriz e filiais), abrindo espaço para as inovações oriundas de outras áreas, a exemplo das tecnologias de informação e comunicação. Investimentos em P\&D configuram-se como elementos fundamentais para atender às novas rotas tecnológicas do setor, necessitando de políticas públicas direcionadas e de financiamentos governamentais para o estímulo às inovações de longo prazo na indústria automotiva. As novas rotas tecnologias que têm se configurado para a indústria automotiva, o desenvolvimento de materiais alternativos e a utilização de nanotecnologias podem estimular a elevação de parcerias para o desenvolvimento de inovações fora da cadeia automotiva, a exemplo de universidades, centros de pesquisas e com empresas fornecedoras. Nesse sentido, se observa a importância da interação do fluxo tecnológico do setor automotivo, classificado na taxonomia como de produção intensiva, com setores de outras classificações na taxonomia de Pavitt, especialmente os setores baseados na ciência. Não obstante, o Estado ainda precisa reconhecer e assumir sua importância no fomento ao desenvolvimento tecnológico e inovativo 
de setores, especialmente quando as inovações envolvem altos riscos, as quais, via de regra, só ocorrem devido à intervenção estatal, seja com financiamentos, seja com o seu aparato normativo e regulador.

Por fim, cabe fazer menção à importância estatal no fomento e condução de estratégias de desenvolvimento industrial, tecnológico e de inovação. Assim sendo, o Estado ainda precisa reconhecer sua importância e assumir posturas mais proativas junto aos setores beneficiados. Isso deve ocorre com ajustes que ainda se fazem necessários na intervenção estatal e na consequente relação estabelecida entre Estado e classe empresarial, especialmente vinculados a incentivos e punições, alcance de metas e tempo de proteção.

Portanto, independentemente do setor, o processo de inovação ocorre via concorrência, sendo motivado pelo reconhecimento (cenário - sinais tecnológicos e econômicos), alinhamento (coerência e adequações em resposta às atividades da concorrência), aquisição (reconhecimento das limitações de base tecnológica próprias e a necessidade de análise integrada de tecnologia e inovação), além da geração (criação através de $P \& D$ ), eficiência nas escolhas (inovação que mais se adeque às necessidades da indústria), execução de novos projetos para a implantação e o gerenciamento de novos produtos, gerando assim o aprendizado e promovendo o desenvolvimento da indústria e dos setores a montante e a jusante.

\section{Referências}

BAHIA, L. D.; DOMINGUES, E. P. Estrutura de inovações na indústria automobilística brasileira. (Texto para discussão n. 1472). Brasília: IPEA, 2010.

BARROS, D.; PEDRO, L. S. O papel do BNDES no desenvolvimento do setor automotivo brasileiro. BNDES 60 anos - perspectivas setoriais. Brasília: BNDES, 2012, p. 98-139.

BRASIL. MINISTÉRIO DA CIÊNCIA, TECNOLOGIA, INOVAÇÕES E COMUNICAÇÕES. Rede Nacional de Ensino e Pesquisa (RNP). MCTI.gov, 2016. Obtido em: <http://www.mcti.gov.br/rnp> Acesso em: 14 ago. 2016.

BNDES - BANCO NACIONAL DO DESENVOLVIMENTO. Plano Brasil Maior. BNDES.gov, $2016 . \quad$ Obtido em: <http://www.bndes.gov.br/SiteBNDES/bndes/bndes_pt/Hotsites/Relatorio_Anual_2011/Capitulos/ atuacao_institucional/o_bndes_politicas_publicas/plano_brasil_maior.html>. Acesso em: 10 ago. 2016.

CAMPOS, B.; RUIZ, A. U. Padrões setoriais de inovação na indústria brasileira. Revista Brasileira de Inovação, v. 8, n. 1, p. 167-210, 2009.

CANÊDO-PINHEIRO, M. A Difusão da Telefonia Fixa nos Domicílios Brasileiros, Economia, Brasília, v. 14, n. 1c, p. 631-643, 2013.

CAPUTO, A. C.; MELO, H. P. de. A industrialização brasileira nos anos de 1950: uma análise da instrução 113 da SUMOC. Estudos Econômicos, v. 39, n. 3, p. 513-538. 2009.

CARVALHO, E. G. de. Inovação tecnológica na indústria automobilística: características e evolução recente. Economia e Sociedade, v. 17, n. 3, p. 429-461, 2008.

CNI - CONFEDERAÇÃO NACIONAL DA INDÚSTRIA. O financiamento do investimento em infraestrutura no Brasil: uma agenda para sua expansão sustentada. Brasília: CNI, 2014. 
CORONEL, D. A.; AZEVEDO, A. F. Z.; CAMPOS, A. C. Política industrial e desenvolvimento econômico: a reatualização de um debate histórico. Revista de Economia Política, v. 34, n. 1, p. 103-119, 2014.

CUNHA, S. Padrões de intervenção do Estado em ciência e tecnologia. Revista de Economia, n. 16. 1992.

DE NEGRI, F.; BAHIA, L.; TURCHI, L.; DE NEGRI, J. A. Determinantes da acumulação de conhecimento para inovação tecnológica nos setores industriais no Brasil - setor automotivo. Brasília: Agência Brasileira de Desenvolvimento Industrial - ABDI, 2008.

DOSI, G. Technical change and industrial transformation. London: MacMillan, 1984.

FREEMAN, C.; SOETE, L. A produção em massa e os automóveis. In: A economia da inovação industrial. São Paulo: Editora Unicamp, 2008, p. 237-276.

GUIDOLIN, S. M. Inovação, estrutura e dinâmica industrial: um mapeamento empírico de regimes tecnológicos da indústria brasileira. 2007. 129 f. Dissertação (Mestrado em Economia) Universidade Federal do Rio Grande do Sul, Porto Alegre, 2007. Obtido em: $<$ http://www.lume.ufrgs.br/bitstream/handle/10183/12589/000631300.pdf?sequence=1>. Acesso em: 29 nov. 2016.

HIGACHI, H. A Abordagem neoclássica do progresso técnico. In: PELAEZ, V.M.; SZMRECSÁNYI, T. (Orgs.). Economia da Inovação Tecnológica. São Paulo: Hucitec, 2006, p. 67-86.

KAMIEN, M.; SCHWARTZ, N. Schumpeterian hypotheses. In: Market structure and innovation. Cambridge: CUP, 1982, p. 22-48.

KIM, L. Estruturas analíticas. In: Da imitação à inovação: a dinâmica do aprendizado tecnológico da Coréia. Campinas: Editora Unicamp, 2005, p. 137-164.

LACERDA, A. C. de; BOCCHI, J. I.; REGO, J. M., BORGES, M. A.; MARQUES, R. M. Anos 1950: Getúlio Vargas e o desafio da indústria pesada. In: LACERDA, A. C. de; BOCCHI, J. I.; REGO, J. M., BORGES, M. A.; MARQUES, R. M. Economia brasileira. 4 ed. São Paulo: Saraiva, 2010a, p.111-141.

LACERDA, A. C. de; BOCCHI, J. I.; REGO, J. M., BORGES, M. A.; MARQUES, R. M. Plano de Metas de Juscelino Kubitschek: planejamento estatal e consolidação do processo de substituição de importações. In: LACERDA, A. C. de; BOCCHI, J. I.; REGO, J. M., BORGES, M. A.; MARQUES, R. M. Economia brasileira. 4 ed. São Paulo: Saraiva, 2010b, p.142-157.

MATTOS, C. Análise do Plano Brasil Maior. Brasília, Nota técnica da Câmara dos Deputados, 2013, p. 26. Obtido em: <http://www2.camara.leg.br/documentos-e-pesquisa/publicacoes/estnottec/areasda-conle/tema10/2013_7665_versao\%20para\%20publicacao.pdf $>$. Acesso em: 10 abr. 2017.

MAZZUCATO, M. O estado empreendedor: desmascarando o mito do setor público vs. setor privado. São Paulo: Portfolio-Penguin, 2014.

NELSON, R. R. Por que as empresas diferem e qual a importância disso? In: As fontes do crescimento econômico. Campinas: Editora Unicamp, 2006, p.165-194.

NELSON, R. R. The co-evolution of technology, industrial structure, and supporting institutions. Industrial and Corporate Change, v.3, n.1, p. 47-63, 1994. Obtido em: <http://icc.oxfordjournals.org/content/3/1/47.full.pdf+html>. Acesso em: 28 abr. 2017.

NELSON, R. R; WINTER, S. G. An evolutionary theory of economic change. Cambridge: Harvard University Press, 1982.

PAVITT, K. Key characteristics of large innovating firms. In: DODGSON, M.; ROTHWELL, R. The handbook of industrial innovation. Cheltenham: Edward Elgar Publishing, 1994, p.357-366.

PAVITT, K. Sectoral patterns of technical change: towards a taxonomy and a theory. Research Policy, v. 13, n. 6, p. 343-373, 1984.

PREBISCH, R. O desenvolvimento da América Latina e alguns de seus problemas principais. In: BIELSCHOWSKY, R. (Org). Cinqüienta anos de pensamento na Cepal. v. 1. Rio de Janeiro: Record, 2000, p. 69-136.

OICA - ORGANISATION INTERNATIONALE DES CONSTRUCTEURS D'AUTOMOBILES. Production Statistics. 2017. Obtido em: <http://www.oica.net/category/production-statistics/>. Acesso em: 30 jun. 2017.

ROSENBERG, N. Joseph Schumpeter: radical economist. In: ROSENBERG, N. Exploring the Black Box. Cambridge, UK: Cambridge University Press, 1994, p.47-61. 